\title{
The Data Sharing Practices and Challenges in Uganda
}

\author{
Isaac Tomusange \\ Muteesa Royal University \\ Muteesa Road, Mengo 14002 \\ Uganda \\ itomusange@mru.ac.ug
}

\author{
Ayoung Yoon \\ Indiana University Indianapolis \\ (IUPUI) \\ 535 W Michigan St. IT563 \\ Indianapolis IN46202 U.S.A. \\ ayyoon@iupui.edu
}

\author{
Norman Mukasa \\ Muteesa Royal University \\ Muteesa Road, Mengo \\ 14002 Uganda \\ mukasan@mru.ac.ug
}

\begin{abstract}
With the rapid development and increased use of information and communication technology (ICT), the demand for data sharing and reuse is growing even in developing countries. This study aims to contribute to the recently emerging discussions on data sharing in developing countries with a focus on the case of Uganda. The goal of this study is to uncover the current practices of and efforts for data sharing in the public sector in Uganda and to understand the relevant stakeholders' perceptions of data sharing and reuse practices/services.
\end{abstract}

\section{Keywords}

Data sharing, developing countries

\section{INTRODUCTION}

With the rapid development and increased use of information and communication technology (ICT), the demand for data sharing and reuse is growing even in developing countries. In the context of developing countries, data sharing offers numerous benefits, as the costs and challenges of data reuse and sharing seem to outweigh those of the initial collection of data. Many have argued that there is a need for data sharing for sustainable development (Rajabifard, et al, 2006). Moreover, considering the potential of using data in policy design, disaster planning, and economic development, government leaders in many developing countries have acknowledged that open data can increase cooperation among government agencies, improve citizen engagement, stimulate innovation, create jobs, and attract foreign investment. However, data sharing also presents considerable challenges in developing countries where resources are

\{This is the space reserved for copyright notices.]

ASIST 2017,. Crystal City, VA | Oct. 27-Nov 1, 2017

[Author Retains Copyright. Insert personal or institutional copyright notice here.] often scarce, sustainability is questionable, and capacities need to be developed (Harrison, 2014). For these reasons, researchers are concerned about how developing countries can secure the full benefits of open data by overcoming the barriers that block the greater impact of data sharing (Davies \& Perini, 2016).

This study aims to contribute to the recently emerging discussions on data sharing in developing countries with a focus on the case of Uganda. The goal of this study is to uncover the current practices of and efforts for data sharing in the public sector in Uganda and to understand the relevant stakeholders' perceptions of data sharing and reuse practices/services. While the issue of data sharing in developing countries has gained recent attention, few research studies have examined data sharing and reuse practices in the context of Uganda despite the recent growth of digital data. This study will provide insights for understanding the data practices and challenges of developing countries by addressing the interesting and dynamic case of Uganda. The poster will present this study's preliminary findings from 20 interviews with four public institutions that have a major impact on data sharing and reuse in Uganda.

\section{DATA SHARING IN UGANDA CONTEXT}

In Uganda, the development of ICT and the Internet has provided an access platform for data sharing and reuse among interested stakeholders, (e.g., scholarly researchers, business executives, political leaders, developers, and security agencies). While policies for data sharing and reuse have not yet been fully defined, Uganda reformed its ICT policy in 1996 to enable government deregulation of the country's telecommunication sector, which led to the development of a platform for effective information sharing and reuse (Ssewanyana \& Busler, 2007). Government agencies have tried to create data platforms for intra- and inter-exchanges so that data can be available for public consumption. For instance, in 2014, the Ministry of Internal Affairs mandated compulsory registration for all Ugandans over the age of 16; this created the first nationwide web of information on the country's citizens (Waiswa \& Okello- 
Obura, 2014). Additionally, semi-autonomous bodies of government, such as the Uganda Revenue Authority and the Kampala City Council authority, provide a significant amount of data for others' use (Mitchinson, 2003).

However, the data sharing and reuse culture in Uganda has not been fully developed yet due to numerous barriers that inhibit these practices. For instance, the National Development Plan noted that the key binding constraints inhibiting the performance of the National Statistics sector were limited use and appreciation of statistics for policy design and formulation (Katusiimeh \& Kangave, 2015). Similarly, the Village Health Team's situational analysis revealed that only $9 \%$ of the health-related data from communities was used for health planning (UNICEF, 2009). Sanyu (2014) also reported that local governments have at least $70 \%$ of the data they need for planning purposes, but that information was lying idle.

In order to better support data sharing and reuse by overcoming these barriers, this study aims to uncover the current practices of and efforts for data sharing in the public sector in Uganda and to investigate the relevant stakeholders' perspectives on the challenges and barriers to creating an open data culture. The project team is currently conducting an interview study with the following four institutions that have a major impact on data sharing and reuse:

- Uganda Bureau of Statistics (UBoS) makes official statistics available free of charge to anyone who can reuse the data.

- Uganda Communications Commission (UCC) under the Ministry of ICT and National Guidance is the government regulatory body that is in charge of protecting the interests and rights of consumers in the communication sector using an effective regulatory and licensing regime.

- The Ministry of Internal Affairs handles the vast majority of personal information about Ugandan citizens due to its massive national identity registration and passport registration project.

- Kampala Capital City Authority (KCCA) represents Ugandan capital's local government body and handles crosscutting functions, such as revenue collection, waste management, security, public space management, transport, and advertising among others.

The study participants include data mangers in each of these four organizations and professionals whose work is relevant to sharing and reusing data (e.g., administrators and mangers in charge of operations, client security, and privacy or public relations). A total of 20 interviews will be conducted (five per each organization) by September 2017.
All the interviews will be audio recorded, and the data will be fully transcribed and analyzed using NVivo, qualitative data analysis software. The data will be analyzed following pre-developed high-level codes from the interview questions. However, the project team will inductively analyze the data to identify any emerging themes under the pre-developed codes.

The findings from the interviews will provide the project team with information about the lifecycle of data in each organization, the management practices used to support data sharing and reuse, and the participants' perspectives on the factors that either facilitate or inhibit data sharing and reuse. The preliminary findings from the interviews will be presented in this poster.

\section{REFERENCES}

Davies, T., \& Perini, F. (2016). Researching the emerging impacts of open data: revisiting the ODDC conceptual framework. The Journal of Community Informatics, 12(2).

Harrison, T. M. (2014, June). Open data and information sharing in developing nations. In Proceedings of the 15th Annual International Conference on Digital Government Research (pp. 311-313). ACM.

Katusiimeh, M. W., \& Kangave, J. (2015). Politics and organizational capacities of selected key fiscal and social institutions in Uganda (No. 2015-12). UNRISD Working Paper.

Mitchinson, R. (2003). Devolution in Uganda: An experiment in local service delivery. Public Administration and Development, 23(3), 241-248.

Sanyu, P. (2014, June 30). Promote the use of data to fight poverty. Newvision.

Ssewanyana, J., \& Busler, M. (2007). Adoption and usage of ICT in developing countries: Case of Ugandan firms. International Journal of Education and Development using ICT, 3(3).

Rajabifard, A., Binns, A., Masser, I., \& Williamson, I. (2006). The role of sub-national government and the private sector in future spatial data infrastructures. International Journal of Geographical Information Science, 20(7), 727-741.

United Nations International Children's Emergency Fund (UNICEF) (2009). Situational Analysis on VHTs in Uganda.

Waiswa, R., \& Okello-Obura, C. (2014). To what extent have ICTs contributed to e-Governance in Uganda?. Library Philosophy and Practice, 0_1 